\title{
Reliability analysis on high-pressure fuel pipe of diesel engine
}

\author{
Weidong Li, Junhong Zhang, Jian Wang, Zhexuan Xu \\ State Key Laboratory of Engines, Tianjin University, Tianjin 300072, People's Republic of China
}

\begin{abstract}
High-pressure fuel pipe is an important component of the fuel injection system of diesel engine, it suffer complex loading from engine. The fatigue life of fuel pipe has great impact on reliability of engine. In this study, the fluid-solid coupling model which considers the action of fuel is established. Analysis on the effect of fuel's pressure oscillation on the mode is carried out. Through the simulation comparisons, the mode frequency and mode shape of each model are all analysed. Base on the fluid-solid coupling model, frequency response analysis is done to study the reliability of high-pressure fuel pipe. The results show that the pressure oscillation of fuel has important influence on the mode frequency. The maximum Stress Tensor and Vibration Velocity appeared at the position of first order mode frequency. It offers the guidance for the design and analysis of High-pressure fuel pipe.
\end{abstract}

\section{Introduction}

High-pressure fuel pipe connects the high pressure fuel injection pump and nozzle, and transfer the fuel to cylinder for the operation of the diesel engine at a certain pressure and velocity through the fuel pressure wave. So it is an important component of the fuel injection system of diesel engine. In recent years, the emission regulations became increasingly strict, and the requirements of engine power performance became higher. In order to solve these problems, it is important to improve the efficiency and the emission performance of diesel engine. Experts had done a lot of research in improving the engine performance. The high-pressure common rail fuel injection system with a high injection pressure was proposed as a new technology applies on the majority of diesel engine. Increased spray pressure has plenty of influence on injection performance, such as acquiring finer spray droplets, enhancing turbulent mixing rate to attain better fuel-air mixture [1], shortening ignition delay time $[2,3]$, reducing soot emission $[4,5]$ and improving specific power [6].

Nowadays, the spray pressure increased even as high as $280 \mathrm{MPa}$, and most of the diesel engine was more than $180 \mathrm{MPa}$ of spray pressure. The increasing of injection pressure has a huge impact on the high pressure fuel pipe. The high-pressure fuel pipe works in a terrible condition and was under two different acting force. One is the pressure oscillations triggered by the injection event, the high pulse pressure acting on the wall inside of fuel pipe directly. Another is the vibrate of high pressure fuel injection pump and cylinder head of diesel engine, the vibration signal due to deformation of high pressure fuel pipe. Both of the acting force would due to the fatigue break of high pressure fuel pipe when the vibration of the diesel engine is getting stronger and the fuel injection pressure become higher. The fatigue failure phenomenon of high-pressure fuel pipe was still in a high frequency. In order to reduce the fatigue failure of high-pressure fuel pipe, the experts doing heave research to improve the performance of fuel pipe [7].

Bae J H [8] has doing the preform design of fuel pipe to preventing the head of high-pressure fuel pipe from folding in the heading process. In his study, the angle, curvature and outer diameter of the die and the length of the trapped part were selected as main parameters in the design of the optimal preform shape that minimizes the radius of folding. Song [9] was carry out a tensile test and a fatigue test to optimize the autofrettage process for improving fatigue life of fuel pipe. And the fatigue analysis was considered not only the compressive residual stresses of the inner surface but also the tensile residual stresses of the outer surfaces of the pipe. Bai SZ [10] analysis the reason of high-pressure fuel pipe's damage by vibration test. Most of the experts analysis the vibration performance of high-pressure fuel pipe when it was empty. But the analysis of high-pressure fuel pipe with fluid-solid coupling was still a little appeared. The fuel flow in high speed had made great impact force on fuel pipe wall. It also had influence on the vibration characteristics of high-pressure fuel pipe.

In this paper, the mode analysis of high-pressure fuel pipe is carried out first. The model of high-pressure fuel pipe will establish by the material property parameters and the shape of pipe that acquire according to the experimental measurement. Based on the fluid-solid coupling method, the mode analysis of high-pressure fuel pipe is held to compare the result of mode analysis of fuel pipe only. The influence on the mode frequency and mode of vibration of high-pressure fuel will prove to 
explain to the importance of fuel flow in high speed. Then the Reliability analysis will carry out to simulation the stress distribution of high-pressure fuel pipe when the diesel engine in normal operation. Through the research, a theoretical basis was provided for fatigue life prediction and fatigue resistance design.

\section{Method of fluid-solid coupling}

Usually the structural dynamic equations of a linear structural system without fluid-solid coupling will be [11]:

$$
\left[M_{e}\right]\left\{\ddot{U}_{e}\right\}+\left[C_{e}\right]\left\{\dot{U}_{e}\right\}+\left[K_{e}\right]\left\{U_{e}\right\}=\left\{F_{e}\right\}
$$

Where $\left[M_{e}\right]$ is the mass matrix; $\left[C_{e}\right]$ is the damping matrix; $\left[K_{e}\right]$ is the stiffness matrix; $\left\{\ddot{U}_{e}\right\}$ is the acceleration; $\left\{\dot{U}_{e}\right\}$ is the Velocity; $\left\{U_{e}\right\}$ is the displacement and $\left\{F_{e}\right\}$ is external excitation.

In the analysis of fluid-solid coupling, it needs to consider both the structural dynamics equation, fluid equation and fluid continuity equation. The fluid-solid coupling equations will be[12]:

$$
\begin{aligned}
& {\left[\begin{array}{cc}
{\left[M_{e}\right]} & {[0]} \\
{\left[M^{f s}\right]} & {\left[M_{e}^{p}\right]}
\end{array}\right]\left\{\left\{\begin{array}{l}
\left\{\ddot{U}_{e}\right\} \\
\left.\ddot{P}_{e}\right\}
\end{array}\right\}+\left[\begin{array}{cc}
{\left[C_{e}\right]} & {[0]} \\
{[0]} & {\left[C_{p}\right]}
\end{array}\right]\left\{\begin{array}{l}
\left\{\dot{U}_{e}\right\} \\
\left.\dot{P}_{e}\right\}
\end{array}\right\}+\right.} \\
& {\left[\begin{array}{cc}
{\left[K_{e}\right]} & {\left[K^{f s}\right]} \\
{[0]} & {\left[K_{e}^{p}\right]}
\end{array}\right]\left\{\left\{\begin{array}{l}
\left.U_{e}\right\} \\
\left\{P_{e}\right\}
\end{array}\right\}=\left\{\begin{array}{c}
\left\{F_{e}\right\} \\
\{0\}
\end{array}\right\}\right.}
\end{aligned}
$$

Where $\left[M^{f_{s}}\right]$ is the element coupling mass matrix, $\left[M_{e}^{p}\right]$ is the fluid element mass matrix, $\left\{\ddot{P}_{e}\right\}$ is the acceleration of fluid, $\left\{\dot{P}_{e}\right\}$ is the Velocity of fluid, $\left\{P_{e}\right\}$ is the displacement of fluid, $\left[C_{p}\right]$ is the damping matrix of fluid, $\left[K_{e}^{p}\right]$ is the stiffness matrix of fluid and the $\left[K^{s s}\right]$ is the element coupling stiffness matrix. In this paper, the pressure oscillation of fuel will consider either.

\section{Reliability analysis on high-pressure fuel pipe}

\subsection{Model}

To compare the mode frequency and mode shape of the empty high-pressure fuel pipe and the fuel pipe fill with fuel, the model of each condition of high-pressure fuel pipe is establish by using hexahedral mesh, shown in Figure 1. The empty high-pressure fuel pipe is made up by 229050 nodes. And the model of fuel pipe fill with fuel is consisted of 740662 nodes. The structure of high pressure oil pipe is very simple, therefore the number of cells is enough to satisfy the accuracy of the calculation. The material of fuel pipe used is a type of seamless steel pipe which is HQ3-8 $\times 3.6-\mathrm{Q} / \mathrm{LG} \mathrm{J} 01$. The properties of the pipe and fuel are listed in Table 1.

Table 1. Material properties table

\begin{tabular}{lcc}
\hline \multicolumn{1}{c}{ Properties } & Pipe & fuel \\
\hline Elastic Modulus(MPa) & $2.1 \mathrm{E} 05$ & - \\
poisson's ratio & 0.3 & - \\
\hline
\end{tabular}

\begin{tabular}{lcc}
\hline Density $\left(\mathrm{t} / \mathrm{mm}^{3}\right)$ & $7.9 \mathrm{E}-09$ & $8.4 \mathrm{E}-10$ \\
velocity of sound $(\mathrm{mm} / \mathrm{s})$ & - & $1.4 \mathrm{E} 06$ \\
\hline
\end{tabular}

(a)

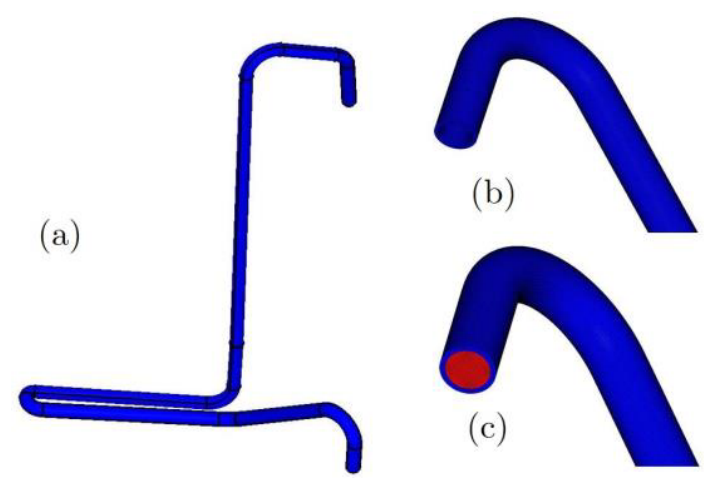

(a) geometry model (b) model of empty fuel pipe

(c) model of fuel pipe fill with fuel

Figure 1. Different models of high-pressure fuel pipe

\subsection{Mode analysis of different model}

In order to study the influence on mode frequency and mode shape when fuel pipe fill with fuel, a finite element model is constructed. The properties of fuel are considered and the pressure oscillation is loaded to the pipe wall. The six degrees of freedoms (DOFs) of the pipe end are constrained. A mode analysis is carried out base on the finite element model. The results of mode frequency of different model are shown in Table 2. Seen from Table 2, the mode frequency of two models has some differences. The mode frequency of fluid-solid coupling model is lower than fuel pipe model in the same order mode. It is because the mass of fuel can reduce the inherent frequency of model. The pressure oscillation which loaded to the pipe wall will produce pre-stress that can influence the mode frequency either. But the different between mode frequencies of two models is small in high order of mode. The density and rigidity of pipe's material has greater influence of mode frequency in high order of mode. Because the pressure oscillation has great influence on modal frequency of fuel pipe, it must be considered when doing the reliability analysis of highpressure fuel pipe.

Table 2. Compare the mode frequency of different model

\begin{tabular}{ccc}
\hline \multirow{2}{*}{ Order } & \multicolumn{2}{c}{ mode frequency } \\
& Fuel pipe only & Fuel pipe with fuel \\
\hline 1 & 83 & 73.6 \\
2 & 160.6 & 155.5 \\
3 & 203.3 & 197.5 \\
4 & 264.5 & 262.6 \\
5 & 314.4 & 311.5 \\
6 & 402.9 & 401 \\
\hline
\end{tabular}

The compare results of mode shape of two models are shown in the figure followed. The first five mode shapes are shown in order of Figure2 to Figure 6. Seen from Figure 2 to Figure 6, the mode shape of the two models are similar. It is because the fuel distribution along the pipe, it means the shape of model does not change. The weight of high-pressure pipe has less effect in the mode shape. Compare the first five mode shape, the 
displacement of fluid-solid coupling model is larger own to its weight.

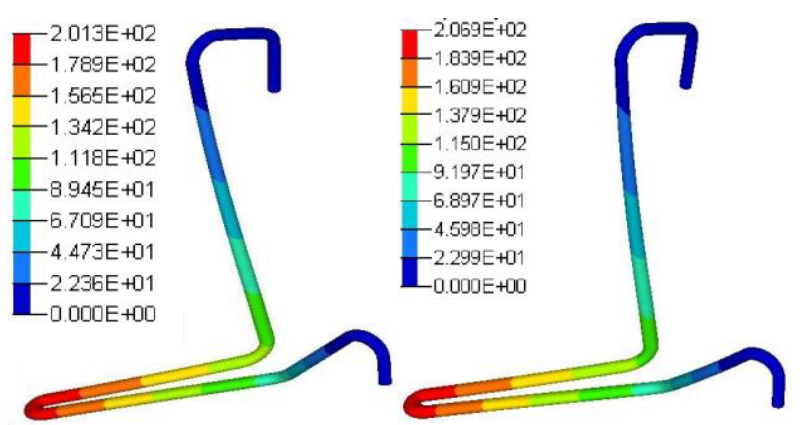

Figure 2. first order mode shape of high-pressure fuel pipe

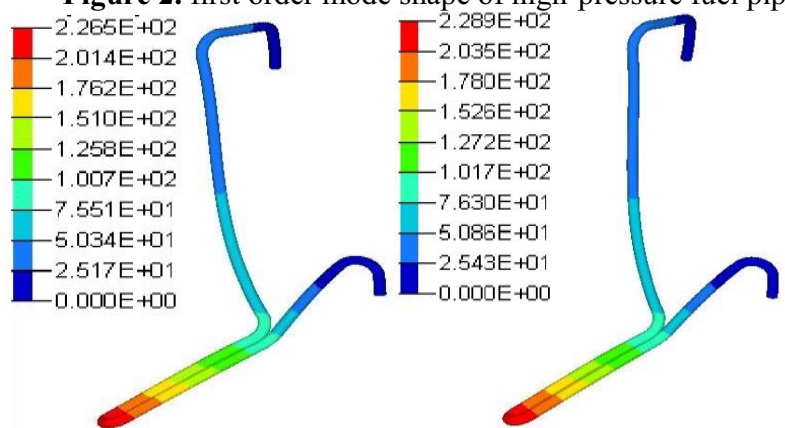

Figure 3. second order mode shape of high-pressure fuel

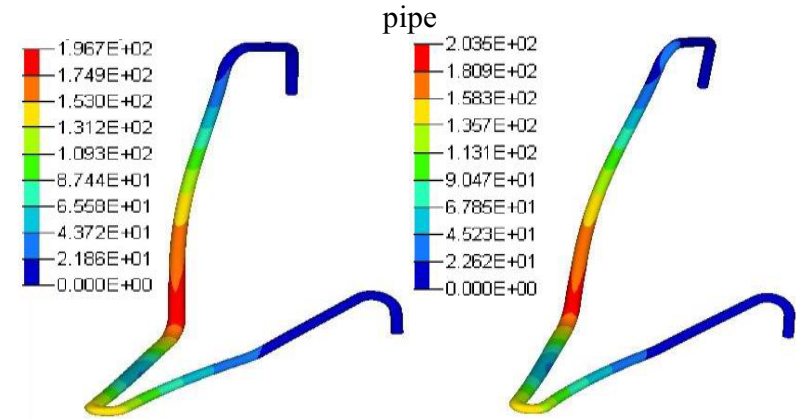

Figure 4. third order mode shape of high-pressure fuel pipe
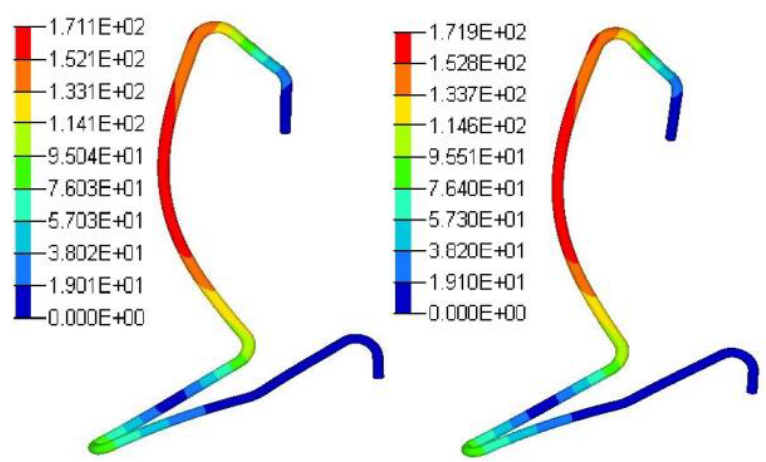

Figure 5. 4th order mode shape of high-pressure fuel pipe

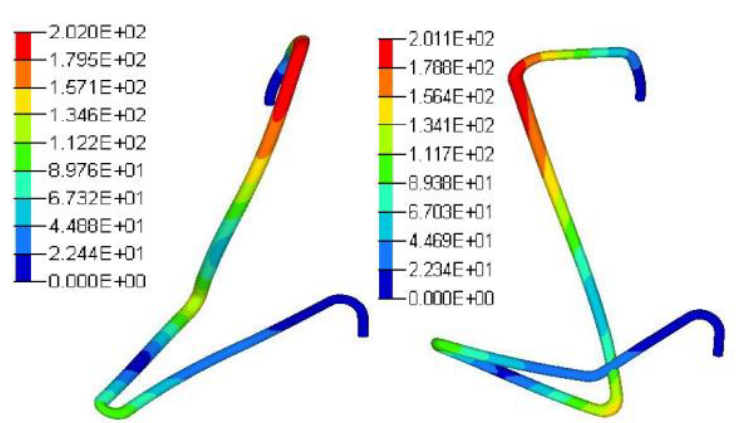

Figure 6. 5th order mode shape of high-pressure fuel pipe

\subsection{Reliability analysis on high-pressure fuel pipe}

To study the reliability of high-pressure fuel pipe, the frequency response analysis of fuel pipe is carried out. The excitation of high pressure fuel injection pump was measure from engine bench test that the engine operation in 2200rpm. Then the excitation is loaded to the end of fuel pipe on corresponding position. The result of stress distribution is shown in Figure 7. From the Figure 7, it can be seen that the maximum stress is distributed around the inflexion point. Because the fuel pipe has better stiffness and it is hard to be out of shape in straight part. So the maximum deformation is occur on inflexion point, and the maximum stress position is the same with maximum deformation.
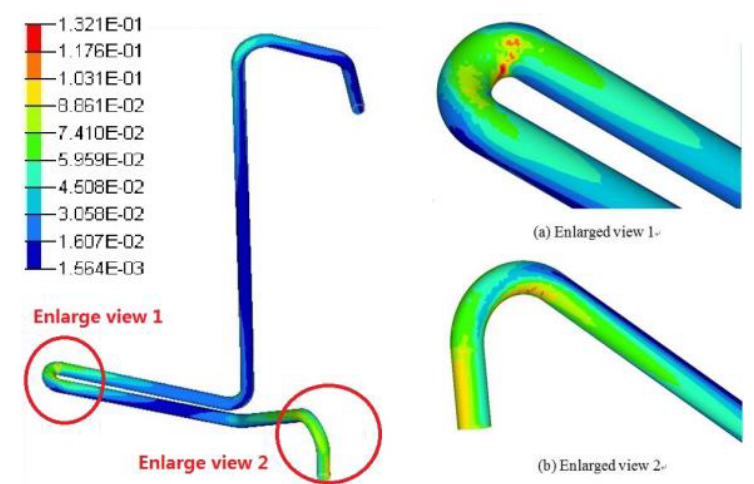

(b) Enlarged view 2

Figure 7. Stress distribution of high-pressure fuel pipe

To study the reliability and vibration characteristic of high-pressure fuel pipe, the Stress Tensor and Vibration velocity of the maximum stress position is analysed. The result of Stress Tensor and Vibration velocity are shown in Figure 8 and Figure 9. As seen in the Figure 7, there is some peak shown in the frequency of $83 \mathrm{~Hz}, 203 \mathrm{~Hz}$ and $401 \mathrm{~Hz}$. The maximum Stress Tensor occur in $83 \mathrm{~Hz}$, it is closed to first order mode frequency. The resonance is happened in this place. Seen from the Figure 9, the maximum vibration velocity also happened in the same frequency. When the engine is operation in $2200 \mathrm{rpm}$, the forced vibration frequency will be $73.3 \mathrm{~Hz}$. The probability of fatigue failure of high-pressure fuel pipe will increase rapidly when the resonance occurred. It's important to optimize the structure of fuel pipe and fixed position. In this way, the mode frequency of fuel pipe will keep away from engine's forced vibration frequency. The reliability and fatigue life of high-pressure fuel pipe can be enhancing greatly.

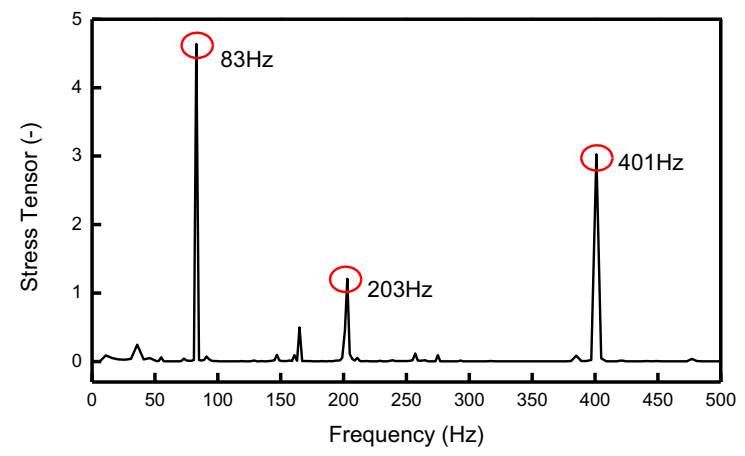

Figure 8. Stress Tensor of the point of maximum stress 


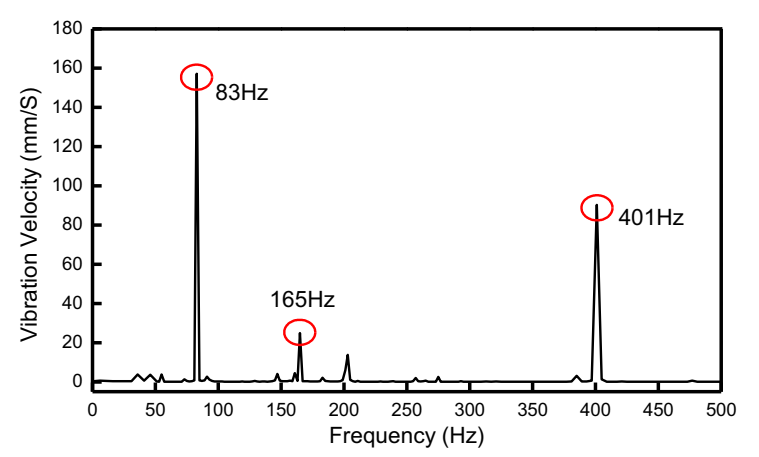

Figure 9. Vibration Velocity of the point of maximum stress

\section{Conclusions}

In this study, the mode analysis based on the finite element model of high-pressure fuel pipe was proposed. The effect of the pressure oscillation of fuel on the mode was analyzed through the simulation of two models. Then the reliability analysis of high-pressure fuel pipe base on fluid-solid coupling model was carried out. Main conclusions can be drawn as follows:

(1) The mode frequencies of the model which consider the fuel action are lower than another model. The mode shapes of two models are similar.

(2) The maximum stress is distributed around the inflexion point. The minimum stress is occur on the middle of each straight part.

(3) The maximum Stress Tensor and Vibration Velocity appeared at the position of first order mode frequency.

\section{References}

1. K.Nishida, W.Zhang, T.Manabe, Effects of microhole and ultra-high injection pressure on mixture properties of D.I.Diesel spray, SAE Technical Paper 2007-01-1890,2007,pp.1353-1361.

2. F.Tao, P.Bergstrand, Effect of ultra-high injection pressureon diesel ignition and flame under highboost conditions, SAE Technical Paper 2008-011603, 2008, pp.1-22.
3. O.A.Kuti, W.Zhang, K.Nishida, etal., Effect of injection pressure on ignition, flame development and soot formation processes of biodiesel fuel spray, SAE Technical Paper2010-32-0053,2010.

4. Can Ö, Celikten I, Usta N. Effects of ethanol additio $\mathrm{n}$ on performance and emissions of a turbocharged in direct injection diesel engine running at different inje ction pressures $[\mathrm{J}]$. Energy conversion and Manageme nt, 2004, 45(15): 2429-2440.

5. Wang X, Huang Z, Kuti O A, et al. Experimental and analytical study on biodiesel and diesel spray characteristics under ultra-high injection pressure[J]. International journal of heat and fluid flow, 2010, 31(4): 659-666.

6. Puhan S, Jegan R, Balasubbramanian K, et al. Effect of injection pressure on performance, emission and combustion characteristics of high linolenic linseed oil methyl ester in a DI diesel engine[J]. Renewable Energy, 2009, 34(5): 1227-1233.

7. Hasan S G A, Kumar G S. Finite Element Analysis a nd Fatigue Analysis of Spur Gear under Random Loa $\operatorname{ding}[\mathrm{J}]$. International Journal of Engineering Science s \& Research Technology, 1(4): 513-523.

8. Song S A, Bae J H, et al. Study of Improvement in Fatigue Life of Fuel Injection Pipe of Common Rail System[J]. Transactions of the Korean Society of Mechanical Engineers A, 2013, 37(8): 991-998.

9. Bai Shu-zhan, Jia Ying-jun, et al. Analysis of Damage of Engine Fuel Injection Pipe Based on Vibration Test [J]. I. C. E \&Powerplant , 2007, 99(3): 49-52.

10. Han K H, Im Y T. Numerical simulation of threedimensional fiber orientation in short-fiberreinforced injection-molded parts[J]. Journal of materials processing technology, 2002, 124(3): 366371.

11. Itoh $T$. Damped vibration mode superposition method for dynamic response analysis[J]. Earthquake Engineering \& Structural Dynamics, 1973, 2(1): 47 57.

12. Zhang Jun-hong, Guo Qian, Wang Jian, et al. Low noise optimization design of plastic oil cooler cover based on the liquid-solid coupling method and multiobjective topological optimization [J]. Journal of Vibration and Shock, 2016, 35(7): 186-191. 